\title{
Editorial
}

Journal of Innate
Immunity
J Innate Immun 2020;12:201-202

DOI: $10.1159 / 000508475$
Received: May 6, 2020

Accepted: May 6, 2020

Published online: May 15, 2020

\section{Once upon a Time}

Once upon a time there was a world free of a COVID-19 pandemic. Though it is not much more than half a year ago since the first case has been reported, it seems that it will take a very long time until we could live a normal life again. Nothing is like before and also the time after COVID-19 will be dramatically changed. Thus, our pre-COVID-19 world appears to be a fairytale, but now when reaching reality we should be aware that it was only a question of time until a pandemic outbreak would cause collateral damage. Other catastrophes are lining up in waiting loops. For instance, each year more than 35,000 patients die in Europe from infections caused by antibiotic-resistant bacteria. These patients can no longer be saved, since physicians run out of treatment options. Given that these numbers are increasing, one does not have to be a prophet to predict the next global catastrophe. The COVID-19 pandemic must therefore act as a wakeup call. As researchers we have to stop dreaming about fairytales and focus on applied problems that will help to prevent additional life-threatening horror scenarios. The question is not whether the next pandemic will happen, but rather when.

In this issue of Journal of Innate Immunity, Sabine Mihm writes about a possible impact of the genetic background in IFNL genes on COVID-19 outcomes [1]. Like many other viruses including the human herpesviruses [2], the oncolytic vesicular stomatitis virus [3], and the human immunodeficiency viruses (HIV) [4], COVID-19 infections trigger massive inflammatory reactions. A better understanding of general principles involved in evoking pathologic inflammatory responses will therefore help to decipher the molecular mechanisms behind the pathology used by the pathogen to cause these severe complications. The respiratory tract is a common port of entry for many viral and bacterial pathogens including COVID-19. Lungs therefore need to be differently protected than other organs. This said, studies focusing on basic pulmonary immune responses will provide important information about the molecular mechanisms which could be used for therapeutic applications [5]. Concerning COVID-19 infections this is of particular importance as patients with underlying diseases such as chronic obstructive pulmonary disease (COPD) are at higher risk to suffer more severe complications. For instance, COPD animal models, as described in the review article by Lloyd Tanner and Andrew Single [6], could be employed for the development of novel COVID-19-relevant models.

Though the corona crisis is dominating our daily life at the moment, we cannot entirely change research focus towards COVID-19. All other infectious diseases will remain a threat to public health and need to be investigated. For instance, Han Gao and colleagues show in an elegant study that survivin, a member of the inhibitor of apoptosis family, can impair the apoptotic machinery in CD4+ $\mathrm{T}$ cells of patients with ulcerative colitis [7]. In their article, the authors found that survivin can interfere with the expression of FasL, which can be considered an important marker of innate immune responses [8]. Though in a different context, also Anna-Maria Andersson and collaborators investigated the role of apoptotic events, by studying neutrophils, one of the primary effector cells of the innate immune system [9-11]. In their contribution the authors demonstrated that efferocytosis of apoptotic neutrophils can enhance the ability of Mycobacterium tuberculosis to control HIV-coinfected macrophages. Apoptosis plays also an important role in the article pub-

\begin{tabular}{ll}
\hline KARGER & $\begin{array}{l}\text { (c) } 2020 \text { The Author(s) } \\
\text { Published by S. Karger AG, Basel }\end{array}$ \\
karger@karger.com & This is an Open Access article licensed under the Creative Commons \\
Attribution-NonCommercial-4.0 International License (CC BY-NC) \\
(http://www.karger.com/Services/OpenAccessLicense), applicable to \\
the online version of the article only. Usage and distribution for com- \\
mercial purposes requires written permission.
\end{tabular}


lished by Irina Korovina and co-workers [12]. The authors describe that myeloid SOCS3 deficiency can regulate angiogenesis via enhanced apoptotic endothelial cell engulfment. These findings may lead to the development of new antiangiogenic therapies, underlining a strong link between regulation of inflammatory reactions and the induction of sprouting angiogenesis. Insects are an ideal model to study the innate immune system. In the last article published in this issue Gyöngyi Cinege and colleagues carried out functional and developmental analysis of hemocyte subsets and immune compartments. To this end, the authors examined cellular immune re- sponses involving multinucleated giant hemocytes from Zaprionus indianus, an Afrotropical drosophilid species [13]. The authors concluded that the unique features of the cell-mediated immunity of this species provides clues towards the understanding of the immune response accomplished by multinucleated giant hemocytes. Together, we hope that despite the corona crisis we were able to assemble an interesting issue that not only covers COVID-19-related research.
Arne Egesten, Lund Heiko Herwald, Lund

\section{References}

1 Mihm S. Covid-19: possible impact of the genetic background in IFNL genes on disease outcomes. J Innate Immun. 2020, DOI: 10.1159/ 000508076.

2 Pontejo SM, Murphy PM, Pease JE. Chemokine subversion by human herpesviruses. J Innate Immun. 2018;10(5-6):465-78.

3 Tomczyk T, Wróbel G, Chaber R, Siemieniec I, Piasecki E, Krzystek-Korpacka M, et al. Immune consequences of in vitro infection of human peripheral blood leukocytes with vesicular stomatitis virus. I Innate Immun. 2018;10(2):131-44.

4 Lemaitre J, Cosma A, Desjardins D, Lambotte $\mathrm{O}$, Le Grand R. Mass cytometry reveals the immaturity of circulating neutrophils during siv infection. J Innate Immun. 2020;12(2): $170-81$.
5 Hartl D, Tirouvanziam R, Laval J, Greene CM, Habiel D, Sharma L, et al. Innate immunity of the lung: from basic mechanisms to translational medicine. J Innate Immun. 2018;10(5-6):487-501.

6 Tanner L, Single AB. Animal models reflecting chronic obstructive pulmonary disease and related respiratory disorders: translating pre-clinical data into clinical relevance. J Innate Immun. 2019 Sep;17:1-23, DOI: 10.1159/ 000502489.

7 Feng BS, Ma N, Zhang YY, Gao H, Zhang C, Li G, et al. Survivin impairs the apoptotic machinery in cd $4+\mathrm{t}$ cells of patients with ulcerative colitis. J Innate Immun. 2019 Jul;22:1-9, DOI: 10.1159/000500546.

8 Francis A, Bosio E, Stone SF, Fatovich DM, Arendts G, MacDonald SP, et al. Markers involved in innate immunity and neutrophil activation are elevated during acute human anaphylaxis: validation of a microarray study. J Innate Immun. 2019;11(1):63-73.
9 Kobayashi SD, Malachowa N, DeLeo FR Neutrophils and bacterial immune evasion. J Innate Immun. 2018;10(5-6):432-41.

10 Chatfield SM, Thieblemont N, Witko-Sarsat V. Expanding neutrophil horizons: new concepts in inflammation. J Innate Immun. 2018; 10(5-6):422-31.

11 Brinkmann V. Neutrophil extracellular traps in the second decade. J Innate Immun. 2018; 10(5-6):414-21.

12 Korovina I, Neuwirth A, Sprott D, Troullinaki M, Poitz DM, Deussen A, et al. Myeloid SOCS3 deficiency regulates angiogenesis via enhanced apoptotic endothelial cell engulfment. J Innate Immun. 2019 Oct;1:1-9, DOI: $10.1159 / 000502645$.

13 Cinege G, Lerner Z, Magyar LB, Soós B, Tóth $\mathrm{R}$, Kristó I, et al. Cellular immune response involving multinucleated giant hemocytes with two-step genome amplification in the drosophilid zaprionus indianus. I Innate Immun. 2019 Sep;25:1-16, DOI: 10.1159/000502646. 